\title{
Do serviço público à Câmara dos Deputados: os parlamentares originários do funcionalismo público no Brasil
}

\author{
Adriano Codato \\ Universidade Federal do Paraná (UFPR)
}

Ana Paula Lopes Ferreira

Universidade Federal do Paraná (UFPR)

Luiz Domingos Costa

Universidade Federal do Paraná (UFPR)

O estudo mostra a variação do perfil político e social dos deputados federais com origem no funcionalismo público que foram eleitos para a Câmara dos Deputados entre 1982 e 2010. Partimos da suposição de que quanto mais alto o cargo ocupado no setor público, menor seria a extensão da carreira cumprida até a Câmara dos Deputados, já que o capital de função potencializaria seus recursos sociais e políticos. Vimos que há diferenças, embora moderadas, no perfil da carreira política entre diferentes escalões do funcionalismo público no Brasil. Contudo, o achado fundamental é a diferença dos parlamentares quando divididos por blocos ideológicos. O sucesso eleitoral dos servidores brasileiros depende menos de atributos ligados à sua função na burocracia do Estado e mais da força que o partido no governo pode exercer sobre o mercado eleitoral e o impulso que pode dar às suas respectivas carreiras políticas.

Palavras-chave: alta administração pública, poder legislativo, agente público, perfil profissional, carreira

\section{Del servicio público a la Cámara de Diputados: los parlamentarios originarios de la función pública en Brasil}

Este trabajo analiza la variabilidad en el rasgo político y social de diputados procedentes del funcionalismo público que han sido elegidos a la Cámara de Diputados, entre 1982 y 2010. Hemos desarrollado y testado la siguiente hipótesis: el nivel (mayor o menor) del

[Artigo recebido em setembro de 2014. Versão final em junho de 2015.] 
puesto ocupado en el sector público influye (respectivamente, disminuyendo o aumentando) la distancia hasta la Cámara - puesto que el capital funcional puede potenciar sus recursos políticos y sociales. Hemos observado que hay diferencias el perfil de la carrera política entre los diferentes escalones de la administración pública en Brasil, aunque sean moderadas. Sin embargo, el hallazgo central es la diferencia de los parlamentarios cuando se los divide por bloque ideológico. El éxito electoral de los servidores brasileños no depende tanto de atributos relacionados con su función en la burocracia estatal; sino que, depende del partido gobernante y de su rol en el mercado electoral impulsando o no sus respectivas carreras políticas.

Palabras clave: alta administración pública, poder legislativo, funcionario público, perfil profesional, carrera

\section{From public service to the Chamber of Deputies: parliamentarians originating from Brazil's civil service}

The present study demonstrates the variations in the political and social profile of federal deputies originating from civil service and elected to the Chamber of Deputies between 1982 and 2010. We stem from the assumption that the higher the position occupied in the public sector, the lower the extension of the career up until the Chamber of Deputies, since positional capital would potentize one's social and political resources. We noticed differences, albeit moderate, in the political career profile across different ranks in Brazil's civil service. Nevertheless, the key finding concerns the differences found between parliamentarians when divided by ideological blocs. The electoral success of Brazilian civil servants depends less on attributes concerning their functions within the State bureaucracy and more on the influence that the ruling party may have over the electoral market and the propulsion it can provide to their respective political careers.

Keywords: top-level public administration, legislative branch, public agent, professional profile, career 


\section{Do serviço público à Câmara dos Deputados: os parlamentares originários do funcionalismo público no Brasil}

Este artigo faz um retrato longitudinal do perfil da carreira e das credenciais sociais e profissionais dos deputados federais com origem no funcionalismo público eleitos para a Câmara dos Deputados entre 1982 e 2010. Esse intervalo de tempo compreende as primeiras eleições gerais desde o fim do bipartidarismo imposto pela Ditadura Militar (em 1980), o longo processo de transição política (começado em 1974 e encerrado em 1985), até a consolidação da democracia eleitoral no Brasil.

$\mathrm{Na}$ literatura internacional sobre a procedência profissional de elites políticas, funcionários públicos são comumente vistos como aqueles com maiores chances de sucesso na carreira parlamentar em decorrência do seu status profissional privilegiado e da sua proximidade quase que "natural" com o meio público (BRAENDLE; STUTZER, 2010, 2011). É possível supor, de maneira realista, que as habilidades aprendidas no exercício da função (gerência de projetos, coordenação de políticas, manejo de leis, etc.), os espaços burocráticos de atuação e, por extensão, as conexões sociais com múltiplos agentes políticos que se podem extrair daí, o status social do cargo ocupado, sua visibilidade política e seu poder decisório, o tempo disponível, em comparação com profissionais liberais, por exemplo, para se dedicar a assuntos públicos etc., constituem-se não apenas em incentivos ou aptidões inatas para atuar na política profissional, mas em recursos mobilizáveis estrategicamente.

Para detectar o tipo de servidor público que se tornou deputado federal no Brasil, consideramos as variações dos atributos sociais e políticos de 211 indivíduos durante oito legislaturas consecutivas, no período entre 1982 e 2010. Esse intervalo abarca a fase mais aguda de transição política da ditadura para a democracia e a fase subsequente de consolidação da moderna democracia liberal brasileira (CODATO, 2005). Analisamos 462 mandatos, já que o mesmo indivíduo pode aparecer em mais de uma legislatura durante o período considerado. Assim, todos os cálculos, exceto os relativos a atributos pessoais, são em função do total de mandatos.

Ao longo do processo de transformação radical do cenário político brasileiro nos últimos 30 anos, a presença dos políticos oriundos do setor público variou ou não? Em que sentido? O contingente e o perfil desses "políticos-funcionários públicos" são os mesmos para partidos de direita ou de esquerda?

Os percentuais dos deputados-funcionários na Câmara dos Deputados ao longo desse intervalo de tempo podem ser lidos na Tabela $1 .^{1}$

\footnotetext{
${ }^{1}$ O material utilizado como fonte para o levantamento de dados de perfil e trajetória e para a classificação profissional desse grupo foram os verbetes do Dicionário histórico-biográfico brasileiro (DHBB) relativos aos deputados eleitos e as biografias disponíveis nos Repertórios Biográficos dos Deputados Brasileiros compilados pela Câmara dos Deputados e acessados como forma de complementar as informações do DHBB (ABREU et al., 2001).
} 
Tabela 1: Total absoluto e relativo dos deputados federais com origem profissional no funcionalismo público eleitos entre 1982 e 2010 para a Câmara dos Deputados

\begin{tabular}{c|c|c|c|c|c|c|c|c}
\hline & $\mathbf{1 9 8 2}$ & $\mathbf{1 9 8 6}$ & $\mathbf{1 9 9 0}$ & $\mathbf{1 9 9 4}$ & $\mathbf{1 9 9 8}$ & $\mathbf{2 0 0 2}$ & $\mathbf{2 0 0 6}$ & $\mathbf{2 0 1 0}$ \\
\hline $\begin{array}{c}\text { Noo de cadeiras } \\
\text { na CD }\end{array}$ & 479 & 487 & 503 & 513 & 513 & 513 & 513 & 513 \\
\hline $\begin{array}{c}\text { deputados- } \\
\text { funcionários }\end{array}$ & 42 & 33 & 43 & 54 & 79 & 81 & 75 & 55 \\
\hline$\%$ & 9,1 & 7,1 & 9,1 & 11,7 & 17,1 & 17,5 & 16,2 & 11,9 \\
\hline
\end{tabular}

Fonte: Observatório de elites políticas e sociais do Brasil (NUSP/UFPR).

$\mathrm{N}=211 ;$ Mandatos $=462$

Nota-se, até 2002, o crescimento constante da participação dos funcionários públicos na Câmara dos Deputados, uma leve queda em 2006, até chegarmos, em 2010, aos mesmos patamares de 1994.

Quando comparados com dados internacionais, esses números não são elevados, visto que os deputados provenientes do funcionalismo nunca ocuparam mais de $17 \%$ do total de cadeiras da Câmara brasileira. A média nesse período é de 12,5\%. Na França, se tomarmos o ano de 1993 para comparação, a participação de ex-funcionários públicos na Assembleia Nacional era de 38\% (contra 11,7\% no Brasil em 1994, ou seja, três vezes maior). Para termos uma ideia do contraste com a Alemanha, em 1995 o Bundestag registrou 40\% das cadeiras ocupadas por exfuncionários (BRAENDle; StUTZER, 2011; DOgAN, 1999).

A Tabela 1 mostra que no Brasil os números são bem menos expressivos, mas não desimportantes. Nas eleições brasileiras de 2008 (municipais) e 2010 (gerais), os candidatos eleitos com as taxas mais altas de votação encontravam-se no setor público, com curso superior completo e eram os detentores de mais alto patrimônio (CORADINI, 2012). Comparando os aspirantes do setor público e privado, Coradini demonstra que os candidatos vindos do setor público tiveram quase o dobro de votos nessas eleições (35,65\%), do que os candidatos que atuavam no mercado (19,88\%).

O artigo 37 da Constituição Federal de 1988 entende por funcionário público o indivíduo "aprovado em concurso público de provas ou de provas e títulos, de acordo com a natureza e a complexidade do cargo ou emprego, na forma prevista em lei, ressalvadas as nomeações para cargo em comissão declarado em lei de livre nomeação" (BRASIL, CF 1988). Consideramos neste artigo como funcionários públicos um contingente mais amplo que essa definição. Utilizamos como parâmetro o critério empregado por Rodrigues (2002): aqueles sujeitos cuja última atividade profissional ou ocupação exercida antes do primeiro mandato eletivo (portanto, antes do début na carreira política) provinha de cargos do setor público de alto, 
médio ou baixo escalão. No caso, o cargo pode ter sido obtido tanto através de concurso público quanto por nomeação superior (política ou administrativa)².

Também a partir de Rodrigues (2002), adaptamos a divisão e a hierarquia entre escalões do funcionalismo de acordo com o poder de tomada de decisões e status social da ocupação. Desse modo, são pertencentes à alta burocracia (alto escalão) os indivíduos cuja última função, cargo ou ocupação era a de diretores, superintendes e chefes de empresas estatais, auditores, juízes, procuradores, promotores, delegados de polícia e outros cargos de nível equivalente. A categoria médio escalão incorpora oficiais das Forças Armadas, supervisores e professores universitários. O baixo escalão inclui professores de ensino fundamental e médio, inspetores técnicos e bancários do setor público, entre outros. Não consideramos como cargos típicos do funcionalismo público brasileiro aquelas posições no Estado ou no governo que são especificamente políticas, tais como secretários municipais e estaduais, chefes de gabinetes políticos e chefes da Casa Civil da Presidência da República.

Como esse terreno é praticamente desconhecido pela literatura nacional de Ciência Política, trabalhamos a partir de uma premissa: políticos originários do funcionalismo público são, em sua maioria, indivíduos com um bom potencial político, mas, de fato, políticos inexperientes, profissionalmente falando. Essa inexperiência é expressa na forma de ingresso na carreira. Eles entram para a política mais velhos do que a média dos parlamentares e sua estreia se dá, na maioria das vezes, já no Legislativo federal, não seguindo um cursus honorum gradual e linear, que vai da vereança à Câmara dos Deputados. O pressuposto que adotamos é que a ocupação de cargos no setor público pode servir como um trampolim importante que permitiria ao candidato queimar etapas na carreira política, dispensando-o da passagem por cargos intermediários de representação (vereador, prefeito, secretário de governo, deputado estadual). Não obstante, tendo em vista a extensão, a complexidade e a diversidade do funcionalismo brasileiro, o tamanho do salto pode estar associado à própria posição ocupada na hierarquia da carreira burocrática. Essa posição na hierarquia tem a ver com a natureza de atividade, o tipo de autoridade e o grau de prestígio do cargo detido. Desse modo, a hipótese que orienta o trabalho é que o tipo da carreira política (mais longa, mais curta) está correlacionada com a posição

\footnotetext{
${ }^{2}$ Esse critério não é o mais seguro, mas é o mais objetivo do ponto de vista metodológico para apontar o status social do parlamentar antes de sua entrada na vida política - o que não ocorre, por exemplo, quando se distribuem os parlamentares com base em autodefinições, pois geralmente eles declaram a sua profissão com base no diploma universitário que possuem, mesmo nunca tendo exercido o ofício. Classificações que aproveitam o diploma de nível superior para indicar a profissão dos políticos não resolvem a questão da verdadeira ocupação exercida. Embora o uso do indicador "última ocupação" possa não corresponder à ocupação predominante na vida do parlamentar, ou à sua atividade econômica principal, esse critério pode ser um preditor melhor das atitudes dos legisladores do que quando se considera seu currículo acadêmico (EDINGER; SEARING, 1967).
} 
hierárquica de origem detida pelo indivíduo no funcionalismo público. Imaginamos que quanto mais alto o cargo ocupado (alto escalão), menor seria a extensão da carreira cumprida até a Câmara dos Deputados, já que o capital ou os recursos técnicos, políticos, jurídicos associados à função exerceriam um efeito maior que o do médio e do baixo escalão. Isso, consequentemente, habilitaria o candidato a chegar mais rápido a uma posição política mais elevada.

O artigo está dividido em três partes. Na primeira seção, expomos, de maneira muito resumida, a discussão da literatura sobre o problema da origem profissional das elites políticas e sobre a questão dos parlamentares com origem no funcionalismo público. Na segunda parte, apresentamos os dados referentes ao perfil socioprofissional desse grupo. Discutimos sexo e áreas de formação superior. Os dados são apresentados por eleição, para que se tenha uma ideia da transformação da categoria ao longo do tempo, e por bloco ideológico, para marcar as diferenças entre os partidos políticos aos quais esses deputados estiveram filiados. Na terceira parte do trabalho, exibimos os dados sobre as carreiras de modo a determinar certos padrões de trajetória política. Destacamos idade de entrada na Câmara dos Deputados, primeiro cargo eletivo e o tempo entre a entrada no serviço público e a estreia no Legislativo federal. Controlamos esses dados em função de três parâmetros: (1) o status do funcionalismo (alto, médio e baixo escalões), (2) a ideologia (esquerda, centro e direita) e (3) a conjuntura política (antes e depois de 2002), tomando a vitória do PT na eleição presidencial como um marco importante que impacta diretamente esse universo.

\section{A variável "ocupação" no estudo de elites}

Há profissões mais propícias que outras para entrar na política, que funcionam como atalhos para uma carreira bem-sucedida? Há relação entre as habilidades ensinadas pelas ocupações exercidas antes da carreira política e as vantagens que se podem extrair daí para informar a atuação do político nos parlamentos depois de eleito? A origem profissional do pessoal político importa para explicar comportamentos e tomadas de posição na arena parlamentar (a defesa de interesses corporativos ou classistas, por exemplo)? Ou os mecanismos de socialização posterior a que os políticos estão submetidos, nos partidos e nos parlamentos, uniformizam e atenuam esse fator?

O objetivo desta sessão é extrair da literatura sobre a estirpe profissional das elites políticas elementos para avaliar o significado da presença de uma dada categoria ocupacional na política institucional.

Ainda que não haja uma relação causal direta, sabe-se que posição na hierarquia social, ocupação profissional e funções exercidas na esfera privada ou pública 
estão vinculadas com o êxito ou o fracasso nas carreiras políticas (GAXIE, 1980). Logo, conhecer as atividades com as quais os legisladores se ocuparam antes de se lançarem no mundo da política profissional deve, em princípio, ajudar a entender as variações nas condições de sucesso ou insucesso na disputa por uma cadeira parlamentar. Da mesma maneira, mapear os atributos políticos e os inputs do background social dos políticos eleitos permite que se olhe na direção inversa, a fim de compreender que transformações na estrutura de oportunidades estão em curso numa dada sociedade. Norris vai mais longe e sustenta que "somente através da interação da estrutura social com as demandas institucionais é possível conhecer o resultado final da representatividade e os filtros do recrutamento político" (NORRIS, 2013). Nesse sentido, o estudo sistemático das fontes sociais de recrutamento das elites políticas pode revelar tanto prestígio individual, como conexões políticas decorrentes do cargo ocupado ou da posição social usufruída em função do cargo, além de habilidades profissionais adquiridas na função para o exercício de um mandato (NORRIS; LOVENDUSKI, 1997).

\section{Profissões de origem: habilidades sociais e recursos econômicos}

Para Weber (1994), o ingresso e a continuidade na vida política estão condicionados não só pela disponibilidade de recursos financeiros e de tempo para se dedicar aos assuntos públicos, mas também pelo nível de afinidade entre as atividades profissionais de origem, de um lado, e os requisitos demandados para a atuação na política parlamentar, de outro. O conhecimento especializado e a experiência advinda do exercício regular de determinadas profissões - direito, jornalismo, ensino superior - são centrais e economizam um grande tempo de aprendizado e treinamento na função parlamentar. Nessa linha, na classificação de Dogan (1999), profissões que predispõem a uma carreira pública são aquelas que oferecem oportunidades por proximidade entre a formação escolar e a experiência exigida para desempenhar a função de representação. Exemplo disso são os parlamentares recrutados na área jurídica. O autor sublinha que esse meio é um rico "viveiro de políticos" em decorrência da vizinhança entre a formação e a experiência desses profissionais e o mundo político-institucional. Além disso, sabese que há, historicamente, uma forte relação entre recrutamento político em certas ocupações numa dada sociedade e a homogeneidade ideológica e de interesses de uma dada elite (CARVALHO, 1996).

Visto o problema por outro ângulo, pode-se dizer que a identidade dos políticos em termos de suas experiências profissionais prévias pode indicar (e às vezes determinar) as condições socioeconômicas que influenciam a decisão de concorrer a um cargo eletivo. Quanto mais bem posicionados na sociedade (em termos de renda e reputação), mais chances efetivas de ser bem-sucedido na política 
institucional. Por analogia, isso pode valer para os burocratas: quanto mais alta a função no Estado, mais fácil ou rápida a trajetória e mais longe se pode ir na carreira parlamentar.

Assim, a presença de funcionários públicos em posições políticas destacadas indicaria não só a detenção de competências específicas para o exercício da função legislativa, mas a capacidade de converter suas prerrogativas sociais e suas vantagens econômicas como agentes do Estado em ativo político. Como lembrou Marenco dos Santos, "na zona de sombras que se situa entre o Estado e a sociedade, um indivíduo pode compensar até mesmo uma origem social modesta com a posição privilegiada que ocupa no Estado, convertido em meio para forjar relações pessoais e respeito político" (MARENCO DOS SANTOS, 1997).

\section{Funcionários na política: um fenômeno recorrente}

Sabe-se que a burocracia de Estado é, no Brasil, uma importante fonte para o recrutamento dos políticos, sendo a presença de legisladores e executivos oriundos da administração pública um fenômeno histórico recorrente desde o período imperial (SOARES, 2008).

Ao longo do século 20, a burocracia esteve presente de modo importante também no Senado brasileiro. Apesar das grandes distâncias sociais que as separam, se somarmos as várias categorias sociais de Estado (militares, juízes, promotores, procuradores, empregados do setor público, servidores de alto escalão e professores), veremos que os senadores-funcionários somavam nada menos de $38,6 \%$ da Casa na segunda metade da década de 1940. O ponto mais baixo da sua participação na Câmara Alta foi na conturbada década de 1930, 14,7\%, mas nos anos 2000 chegaram a ocupar 1/3 das cadeiras (CODATO; COSTA; MASSIMO, 2014).

Em pesquisas realizadas na Europa, Dogan (1999) observa uma tendência de crescimento de funcionários públicos no parlamento francês no período de 1871 a 1993. Somente no intervalo 1946-1993, o percentual de funcionários na Assembleia Nacional mais que dobrou, passando de $14 \%$ para $38 \%$. Esse caso, de resto, acompanha a tendência geral dos países europeus. Houve uma alta no recrutamento de indivíduos originários do funcionalismo no século 19 , uma queda no período entre as duas guerras mundiais, e um aumento desse contingente no pós-Segunda Guerra Mundial (CotTA; TAVAres de Almeida; Roux, 2004). Na Áustria, o Estado foi o principal fornecedor de candidatos recrutados pelos partidos políticos: depois de 1945, mais da metade dos membros do parlamento vieram do funcionalismo público, tendência essa que continuou importante no decorrer das décadas seguintes. Na primeira década dos anos 2000, esse grupo profissional representava quase $55 \%$ dos parlamentares austríacos. Na mesma temporada, na 
Alemanha, essa categoria representava nada menos do que $40,2 \%$ do Bundestag (BRAENDle; STUtZer, 2010).

Quando se olha o assunto da perspectiva da Europa ocidental e oriental é forçoso reconhecer que "uma certa forma de serviço de Estado foi, durante longos períodos, uma das experiências mais significativas dos membros do Parlamento" (COTTA; TAVARES DE AlMEIDA; Roux, 2004, p. 102). Tomando por base 11 países europeus ${ }^{3}$ pesquisados no EurElite Project, vê-se que nos anos 1980 havia em média nesses Legislativos 35\% de representantes oriundos do serviço público. Nos anos 1990, esse número chegou próximo aos 40\% (COTTA; TAVARES DE ALMEIDA, 2007, p. 52).

Nos países do Báltico, os ex-funcionários públicos tiveram uma participação crescente na política parlamentar depois da desintegração da União Soviética. Na Estônia, essa categoria cresceu de 20\% em 1990 para 44,6\% em 2010. O mesmo ocorreu na Letônia: nesse período, o contingente de políticos-funcionários públicos passou de $14,9 \%$ para $24 \%$. O parlamento lituano, por sua vez, se aproxima da Câmara dos Deputados brasileira: a categoria foi de 6,8\% para 17,3\% entre 1990 e 2010. Na Finlândia, no intervalo 1987-1997, os funcionários públicos chegaram a formar 30\% do Legislativo (KUKLYS, 2013).

A elevada presença de servidores públicos na política parlamentar pode estar associada ao fato de usufruírem de generosas licenças sem prejuízo dos ordenados enquanto trabalham em suas campanhas eleitorais, um recurso importante que indivíduos provenientes de outras profissões não detêm. No Brasil, está previsto afastamento remunerado aos servidores públicos por um período de três meses antes do pleito, até o décimo dia seguinte ao da eleição ${ }^{4}$. A flexibilidade em termos de tempo e a possibilidade de negociar funções e adiar tarefas que essa categoria profissional possui também é fundamental para liberar a agenda pessoal para atuar nos partidos políticos, tanto para a construção de candidaturas, como para a ocupação de posições estratégicas na burocracia partidária. Além de tudo isso, é sempre possível retornar à antiga função no Estado caso se fracasse na campanha, o que minimiza o risco individual embutido nessa empreitada.

Todavia, não se deve falar de funcionário público e de suas relações com a carreira política em abstrato. Quando se olha esse grupo profissional mais de perto, nota-se que há variações importantes no tipo de diploma universitário detido, na filiação partidária dominante, na forma de estreia na política, e que essas características variam ao longo do tempo. Nas próximas seções, faremos uma exposição dos dados

\footnotetext{
3 Dinamarca, Finlândia, França, Alemanha, Itália, Holanda, Noruega, Portugal, Espanha, Reino Unido e Hungria.

4 Portal do Servidor. Legislação servidor público, 2014. Disponível em: <http://www.portaldoservidor.ba.gov.br/ noticias/orienta\%C3\%A7\%C3\%A3o-o-servidor-p\%C3\%BAblico-e-legisla\%C3\%A7\%C3\%A3o-eleitoral> Acesso em: 14 jul. 2014.
} 
descritivos levantados sobre esse grupo profissional na Câmara dos Deputados do Brasil desde 1982. Essa é uma expedição exploratória, visto que o conhecimento da sociografia característica desse grupo na política brasileira é praticamente nulo.

\section{Perfil socioprofissional dos deputados federais "funcionários"}

Afinal, quem são esses políticos? Essa é a pergunta básica que se faz ao pensarmos no grupo de representantes composto por funcionários públicos que se engajam na política no Brasil. Nesta seção, serão expostos dados referentes ao perfil dessa categoria na Câmara dos Deputados, levando em conta sexo e formação acadêmica. Na seção seguinte, trataremos apenas dos atributos políticos.

\section{Mulheres entre os funcionários}

A participação feminina na política brasileira é bastante baixa e no Legislativo federal não é diferente: em 2014, apenas 8,6\% do total das cadeiras da Câmara dos Deputados eram detidas por mulheres (44 deputadas entre 513 representantes) (INTER-PARLIAMENTARY UNION, 2014). Ao levantarmos o perfil desses 211 deputados que passaram pela Câmara baixa entre 1982 e 2010, verificamos que o grupo é composto, na sua grande maioria, por homens, $89 \%$ do total, enquanto que as mulheres representam somente $11 \%$ do universo estudado. De todas as 256 mulheres eleitas para a Câmara dos Deputados no período 1982-2010, apenas 51 $(19,9 \%)$ delas vieram do funcionalismo público. Há, dessa forma, nesse contingente, um pouco mais de mulheres do que na Câmara em geral ${ }^{5}$. Na Tabela 2, é possível notar a variação da presença de homens e mulheres ao longo do tempo.

Tabela 2: Percentual de homens e mulheres com origem profissional no funcionalismo público eleitos para Câmara dos Deputados entre 1982 e 2010

\begin{tabular}{l|c|c|c|c|c|c|c|c}
\hline Sexo & 1982 & 1986 & 1990 & 1994 & 1998 & 2002 & 2006 & 2010 \\
\hline Homens & 100 & 84,8 & 83,7 & 88,9 & 91,1 & 87,7 & 88,0 & 87,3 \\
\hline Mulheres & 0 & 15,2 & 16,3 & 11,1 & 8,9 & 12,3 & 12,0 & 12,7 \\
\hline Total & 100 & 100 & 100 & 100 & 100 & 100 & 100 & 100 \\
\hline
\end{tabular}

Fonte: Observatório de elites políticas e sociais do Brasil (NUSP/UFPR).

$\mathrm{N}=211 ;$ Mandatos $=462$

\footnotetext{
${ }^{5}$ Para uma exploração pormenorizada das características desse subgrupo, ver (Ferreira; Lemos; Sirino, 2015). As autoras lembram que "No caso das deputadas provenientes do serviço público, a dificuldade em conciliar jornadas de diferentes aspectos com a vida política poderia ser amenizada em decorrência da flexibilidade de horário e/ou de jornadas reduzidas (após atingir estabilidade no cargo, existe a possibilidade de solicitar a redução da jornada de trabalho para seis horas diárias), o que pode ser uma vantagem se comparada à condição das demais mulheres para se lançar na política" (p. 2). Mesmo assim, seguem sendo baixas as taxas também aqui.
} 
Comparando-se a presença de mulheres com os homens, nota-se a grande discrepância entre os dois sexos também entre os funcionários-deputados. A adoção do regime de quotas nos anos 1990 e depois seu aperfeiçoamento em 2009 não melhorou muito, paradoxalmente, o problema, já que nunca mais se atingiram as taxas das eleições de 1986 (15\%) e 1990 (16\%).

\section{Formação acadêmica}

Para avaliar as áreas de formação acadêmica desses parlamentares, agrupamos os cursos de graduação por afinidade temática e/ou profissional em cinco grupos diferentes: 1) Ciências exatas e da terra (Engenharias, Agronomia, Física, Matemática, Geologia, Química Industrial, Ciências Naturais, Tecnológico, Geografia e Farmácia); 2) Ciências biológicas (Medicina, Enfermagem, Educação Física, Psicologia e Odontologia); 3) Ciências humanas (Serviço Social, Direito, História, Letras, Pedagogia, Ciências Sociais, Economia, Administração, Contabilidade, Jornalismo, Relações Públicas, Turismo, Arquitetura e Teologia); 4) Formação militar; e 5) sem formação acadêmica ${ }^{6}$.

Tabela 3: Áreas de formação superior dos deputados federais originários do funcionalismo público eleitos entre 1982 e 2010 para a Câmara dos Deputados (\%)

\begin{tabular}{lcccccccc}
\hline Curso & 1982 & 1986 & 1990 & 1994 & 1998 & 2002 & 2006 & 2010 \\
\hline $\begin{array}{l}\text { Ciências exatas } \\
\text { e da terra }\end{array}$ & 11,9 & 18,2 & 20,9 & 22,2 & 27,8 & 30,9 & 36,0 & 30,9 \\
$\begin{array}{l}\text { Ciências } \\
\text { biológicas }\end{array}$ & 0 & 3,0 & 4,7 & 13,0 & 11,4 & 17,3 & 16,0 & 16,4 \\
$\begin{array}{l}\text { Ciências } \\
\text { humanas }\end{array}$ & 78,6 & 63,6 & 65,1 & 55,6 & 50,6 & 48,1 & 44,0 & 47,3 \\
$\begin{array}{l}\text { Formação } \\
\text { Militar }\end{array}$ & 7,1 & 9,1 & 7,0 & 3,7 & 3,8 & 1,2 & 0 & 1,8 \\
$\begin{array}{l}\text { Sem formação } \\
\text { Total }\end{array}$ & 2,4 & 6,1 & 2,3 & 5,6 & 6,3 & 2,5 & 4,0 & 3,6 \\
\hline
\end{tabular}

Fonte: Observatório de elites políticas e sociais do Brasil (NUSP/UFPR).

$\mathrm{N}=211 ;$ Mandatos $=462$

Entre esse grupo, há um percentual muito baixo, quase nulo, de indivíduos sem diploma superior. Do ponto de vista da escolaridade formal, portanto, os deputadosfuncionários públicos estão acima da taxa de escolaridade formal do conjunto do plenário da Casa, que está situado na faixa dos 82\% (RODRIGUES, 2002, p. 99). Esses valores estão ligados às exigências de ingresso na maioria das carreiras do serviço civil no Brasil.

${ }^{6}$ Consideramos sempre a primeira graduação em questão quando havia mais de uma. 
Mas há outros dados mais notáveis na Tabela 3. Há uma queda da formação humanística de quase $79 \%$ do universo em 1982 para pouco mais de 45\% em 2010, embora permaneça como o maior contingente nesse grupo. No mesmo sentido, mas com valores contrários, verificamos que o total de deputados-funcionários graduados em ciências exatas e da terra triplicou entre 1982 e 2006, estabilizandose em $1 / 3$ desse pessoal político na atual legislatura. Em terceiro lugar, destaque-se o quase desaparecimento dos militares desse grupo de deputados federais. Eles, que não eram muitos em 1982 (7\%), foram diminuindo com o tempo e ficaram reduzidos a menos de $2 \%$ em 2010 , no curso do grande processo de civilização da classe política nacional, entre o fim do regime ditatorial-militar e a democracia atual. Por fim, ciências biológicas vêm crescendo constantemente e, apesar de algumas oscilações, foi de 0\% no início da série para 16\% em 2010.

Gráfico 1: Percentual de deputados com origem no alto, médio e baixo funcionalismo público eleitos no Brasil por área de formação universitária entre 1982 e 2010

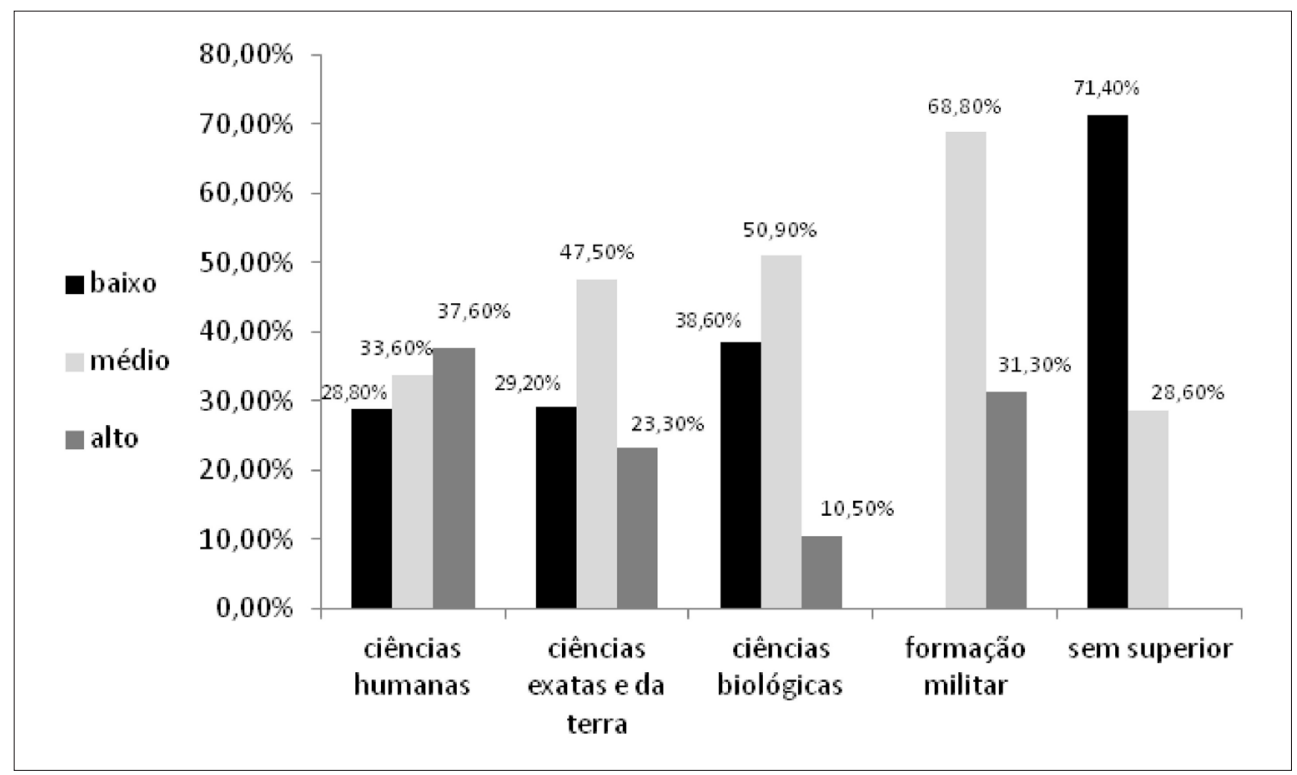

Fonte: Observatório de elites políticas e sociais do Brasil (NUSP/UFPR).

$\mathrm{N}=211 ;$ Mandatos $=462$

Quando desagregamos mais ainda os dados, agora por cursos de graduação específicos, temos algumas evidências interessantes. Entre as especialidades na formação universitária, o Direito é há muito tempo, como se sabe, uma das mais frequentes nos poderes legislativos do mundo (MILLER, 1995). O Brasil não foge à regra, mas há mudanças importantes. Neiva \& Izumi (2012) associaram a redução das formações mais tradicionais ao processo de democratização e de inserção 
de novas categorias sociais na representação política no País. Nesse sentido, se considerarmos apenas o universo de deputados-funcionários, 52\% deles possuíam, em 1982, diploma de bacharel em Ciências Jurídicas. Esse percentual oscila ao longo das legislaturas, tendo seu menor valor em 2006 com 21\%. Ao mesmo tempo, aumentou significativamente a participação de engenheiros no período, de 9,5\% em 1982 para $28 \%$ em 2010.

Se agruparmos os dados de formação universitária pelos escalões de origem (alto, médio e baixo) dos funcionários eleitos deputados, teremos a distribuição mostrada no Gráfico 1.

Não é surpresa que da categoria dos sem curso superior, pouco mais de $70 \%$, sejam funcionários de baixo escalão. Mas não estava dentro do esperado que o maior contingente das ciências humanas fosse originário do alto escalão (37\%). É provável que a presença do Direito nessa classe tenha conduzido os resultados.

\section{A carreira política dos servidores públicos}

Para estimar a extensão e o perfil da carreira desses deputados eleitos após 1982, levamos em consideração três informações: (1) a idade de entrada na Câmara; (2) o tipo e o nível do primeiro cargo eletivo conquistado (o début na carreira política); (3) a média de anos de carreira entre a entrada no Estado (exercício do primeiro cargo público) e a primeira eleição para a Câmara dos Deputados. Controlamos esses dados em função de três variáveis: estrato a que pertenciam originalmente no serviço público, bloco ideológico ${ }^{7}$ e se foram eleitos antes ou depois de 2002. Como em 2002 há uma substituição importante do partido no poder, queremos ver se há algum efeito e qual o efeito disso sobre o contingente estudado.

\section{Escalões da burocracia e degraus da política}

Os deputados federais que exerceram cargos públicos no alto escalão do funcionalismo - o que inicialmente foi imaginado por nós como uma porta de entrada mais rápida e mais fácil para a política parlamentar - têm baixa representatividade entre os eleitos, contrariando, portanto, a nossa suposição inicial. Quando considerados em bloco, pouco menos de um terço desses deputados federais (30,3\%) proveio dos estratos superiores da burocracia. Tomando todo o período 1982-2010, o que se constatou foi que praticamente a metade $(39,6 \%)$ dos ex-servidores tem

\footnotetext{
${ }^{7}$ Nesse trabalho, os partidos políticos foram agregados por blocos ideológicos com base na tabela comparativa desenvolvida por (TARouco; MAdeIRA, 2013) e (CodATO; CostA; CERVI, 2013). Na Esquerda, estão as seguintes agremiações: PDT, PT, PSB, PSOL, PPS, PCdoB; Centro: PMDB, PSDB, PV; Direita: DEM/PFL, PPB, PP, PRB, PDS, PRN, PDC. PL/PR, PTB, PSC, PSP, PRP, PMN, PTdoB, PSD, PPR, PTR.
} 
origem no médio escalão. Eles são principalmente professores universitários e representam $21,3 \%$ dos 183 parlamentares recrutados nesse estrato. O baixo escalão do funcionalismo integra esses números com $30,1 \%$ do total.

A Tabela 4 dá uma ideia mais clara da transformação desse perfil a cada rodada eleitoral e mostra que 1990 foi o ano de mudança nesse grupo: a partir daí, a alta burocracia sofre uma queda considerável (de $43 \%$ para $22 \%$ ), ao mesmo tempo em que cresce o número dos deputados que chegam à Câmara oriundos das funções socialmente menos prestigiadas (em termos de salário, status e poder) do Estado: em 2010 , são quase $80 \%$ desse grupo de parlamentares oriundos do médio (40\%) e baixo (38\%) escalões.

Tabela 4: Total absoluto e relativo dos deputados federais com origem profissional no funcionalismo público eleitos entre 1982 e 2010 por escalão

\begin{tabular}{l|c|c|c|c|c|c|c|c}
\hline Estrato & 1982 & 1986 & 1990 & 1994 & 1998 & 2002 & 2006 & 2010 \\
\hline \multirow{2}{*}{ Alto } & 18 & 15 & 17 & 17 & 20 & 20 & 29 & 12 \\
\cline { 2 - 9 } & 42,9 & 45,5 & 39,5 & 27,8 & 25,3 & 24,7 & 38,7 & 21,8 \\
\hline \multirow{2}{*}{ Médio } & 13 & 10 & 19 & 22 & 34 & 38 & 25 & 22 \\
\cline { 2 - 9 } & 31,0 & 30,3 & 44,2 & 40,7 & 43,0 & 46,9 & 33,3 & 40,0 \\
\hline \multirow{2}{*}{ Baixo } & 11 & 8 & 7 & 15 & 25 & 23 & 21 & 21 \\
\hline \multirow{2}{*}{ Total percentual } & 26,2 & 24,2 & 16,3 & 27,8 & 31,6 & 28,4 & 28,0 & 38,2 \\
\hline
\end{tabular}

Fonte: Observatório de elites políticas e sociais do Brasil (NUSP/UFPR).

$\mathrm{N}=211 ;$ Mandatos $=462$

A partir das eleições de 1990, é crescente a participação de deputados vindos do médio funcionalismo público e, exceto em 2006, seus percentuais são sempre superiores aos dos demais escalões. Em 2010, a taxa de burocratas do baixo funcionalismo que chega à Câmara quase empata com o médio funcionalismo, o que pode revelar uma nova tendência no perfil desses eleitos.

Quando separamos esses dados por blocos ideológicos, em função da identidade partidária dos deputados (Gráfico 2), vemos uma afinidade entre perfil ideológico e estrato funcional de origem: a direita brasileira recruta minoritariamente seus quadros no baixo funcionalismo e a esquerda recruta minoritariamente seus quadros no alto funcionalismo público. As informações estão apresentadas por resíduos padronizados. O limite estatisticamente significativo que nos permite dizer que não há aleatoriedade na distribuição dos dados está acima (positiva ou negativamente) de 1,96. Pode-se interpretar a superação dos resíduos como uma associação do tipo chi-square. 
Gráfico 2: Deputados com origem no funcionalismo público eleitos entre 1982 e 2010 por bloco ideológico e por escalão (resíduos padronizados)

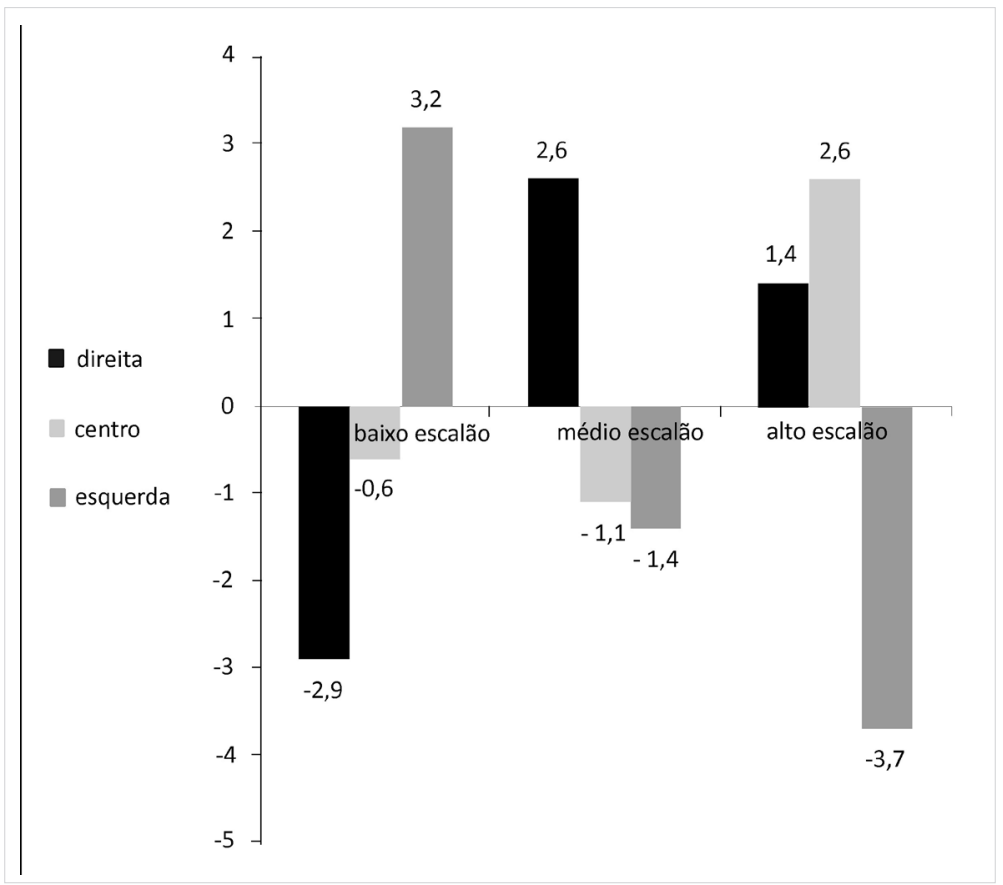

Fonte: Observatório de elites políticas e sociais do Brasil (NUSP/UFPR).

$\mathrm{N}=211 ;$ Mandatos $=462$

Esquerda: PDT, PT, PSB, PSOL, PPS, PCdoB; Centro: PMDB, PSDB, PV; Direita: DEM/PFL, PPB, PP, PRB, PDS, PRN, PDC. PL/PR, PTB, PSC, PSP, PRP, PMN, PTdoB, PSD, PPR, PTR.

Essa constatação reforça os achados de Rodrigues $(2002,2006)$ sobre a coerência entre partido, ideologia e perfil social dos parlamentares no Brasil. Quando se toma o conjunto dos deputados federais (eleitos em 1998 e 2002, os anos do seu experimento), o que se verifica é a mesma associação: ocupações altas e médias na direita e baixas na esquerda.

Esse grupo de deputados entra no serviço público com idade média de 22,4 anos e eles chegam à Câmara dos Deputados em torno dos 39,3 anos, em média. A Tabela 5 mostra que, também nesse caso, há uma diferença importante entre direita e esquerda: políticos novatos com origem profissional no funcionalismo tendem a chegar à $C D$ pelos partidos de direita. $56,6 \%$ dos direitistas estreiam na Câmara muito jovens, entre os 18 e os 30 anos de idade. Políticos de esquerda chegam bem mais tarde, a maioria deles depois dos 46 anos de idade. 
Tabela 5: Percentual de deputados federais com origem no funcionalismo conforme a idade de entrada na Câmara dos Deputados

\begin{tabular}{ccccc}
\hline $\begin{array}{c}\text { Classes de } \\
\text { idade }\end{array}$ & Direita & Centro & Esquerda & Total \\
\hline $18-30$ & 56,6 & 26,3 & 17,2 & 100,0 \\
$31-45$ & 30,8 & 35,4 & 33,8 & 100,0 \\
$46-60$ & 13,3 & 22,2 & 64,4 & 100,0 \\
61 ou mais & 41,7 & 50,0 & 8,3 & 100,0 \\
\hline
\end{tabular}

Fonte: Observatório de elites políticas e sociais do Brasil (NUSP/UFPR).

$\mathrm{N}=211 ;$ Mandatos $=462$

Os dados referentes ao cargo de estreia na carreira mostram que a principal porta desse grupo para a política é mesmo a própria Câmara dos Deputados. Entram na carreira, portanto, já num posto muito elevado. Dos 211 ex-funcionários públicos eleitos no período entre 1982 e 2010, 37,4\% debutaram na política pela Câmara dos Deputados e $24,7 \%$ pelas Assembleias Legislativas. $28,4 \%$ começaram na política como vereadores, $7,4 \%$ como prefeitos ou vice-prefeitos e somente $2,2 \%$ como governadores ou vice-governadores.

Verificando esses percentuais por ano de eleição (Tabela 6), notamos que há predominância de estreantes na Câmara dos Deputados em 1982 (45\%), em 1986 (48\%), em 1990 (58\%) e em 1994 (44\%). A partir de 1998, há uma virada completa e as Câmaras Municipais passam a ser o canal de ingresso para $40 \%$ dos eleitos, fenômeno que se repete em 2002. Nas eleições de 2006 e de 2010, contudo, a Câmara dos Deputados volta a importar e os valores praticamente empatam com os da Câmara de Vereadores. De toda forma, o dado que permanece constante é o caráter minoritário de ingresso na política por cargos no Executivo.

Tabela 6: Primeiro cargo eletivo dos deputados federais originários do funcionalismo público eleitos entre 1982 e 2010

\begin{tabular}{l|c|c|l|l|l|l|l|l}
\hline Cargo & 1982 & 1986 & 1990 & 1994 & 1998 & 2002 & 2006 & 2010 \\
\hline Vereador & 19,0 & 12,1 & 20,9 & 22,2 & 40,5 & 35,8 & 30,7 & 27,3 \\
\hline Prefeito & 14,3 & 6,1 & 0,0 & 7,4 & 3,8 & 4,9 & 10,7 & 12,7 \\
\hline Deputado Estadual & 19,0 & 24,2 & 16,3 & 24,1 & 24,1 & 27,2 & 26,7 & 29,1 \\
\hline Deputado Federal & 45,2 & 48,5 & 58,1 & 44,4 & 30,4 & 30,9 & 32,0 & 29,1 \\
\hline Governador & 2,4 & 9,1 & 4,7 & 1,9 & 1,3 & 1,2 & 0 & 1,8 \\
\hline Total & 100 & 100 & 100 & 100 & 100 & 100 & 100 & 100 \\
\hline
\end{tabular}

Fonte: Observatório de elites políticas e sociais do Brasil (NUSP/UFPR). 
Em relação ao tempo médio de carreira entre a assunção do primeiro posto ocupado no funcionalismo do Estado e o último cargo (que pode ser cargo público ou posição eletiva) antes da chegada na Câmara dos Deputados, o que se vê é um crescimento significativo de tempo medido em anos entre as oito legislaturas, passando de uma média de 10 anos de carreira no serviço civil, até a estreia na Câmara dos Deputados em 1982, para quase o dobro disso, 18 anos em 2010. Uma mudança tão grande no tempo de carreira pode ser um indicador de profissionalização política, não exatamente desse grupo em especial, mas do campo político nacional que passa a exigir dos pretendentes a deputado o cumprimento de uma trajetória mais linear e gradual.

\section{Ideologia e governo: antes e depois do PT}

Tomando esse grupo de políticos como um todo, vê-se que há uma distribuição relativamente uniforme entre direita, centro e esquerda. Cada posição ideológica congrega praticamente $1 / 3$ dos deputados. A maioria foi eleita por partidos de direita $(35,5 \%)$, mas ela não é muito maior que os eleitos por partidos de esquerda $(32,3 \%)$. Esses também estão à frente, mas por pouco, dos eleitos por partidos de centro (32,1\%).

A dimensão dos blocos ideológicos muda totalmente quando analisamos as transformações no perfil partidário dos eleitos ao longo do tempo.

Houve, entre o fim do bipartidarismo e o regime da democracia atual, uma queda importante dos ex-funcionários públicos eleitos por partidos de direita: eles passaram da maioria desse grupo, 57\% em 1982, para apenas 25\% em 2010. Nesse movimento, a esquerda cresceu 17 vezes, saltando de 2,4\% no início da série para $42 \%$ ao fim dela, como mostra o Gráfico 4. O ponto de virada aqui é novamente a eleição de 1998.

\section{Gráfico 3: Percentual de deputados federais originários do funcionalismo público eleitos entre 1982 e 2010 por bloco ideológico}

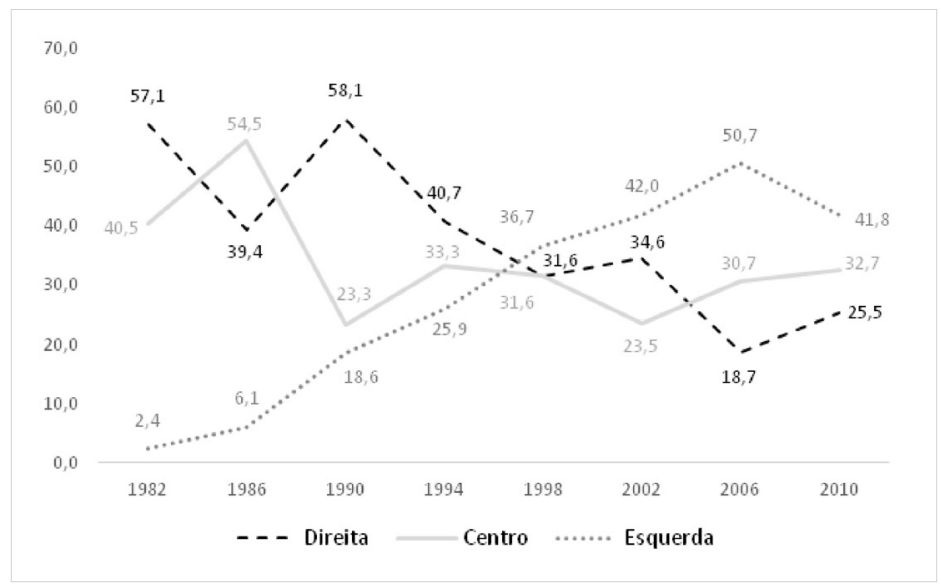

Fonte: Observatório de elites políticas e sociais do Brasil (NUSP/UFPR). $\mathrm{N}=211$; Mandatos $=462$

Esquerda: PDT, PT, PSB, PSOL, PPS, PCdoB; Centro: PMDB, PSDB, PV; Direita: DEM/PFL, PPB, PP, PRB, PDS, PRN, PDC. PL/PR, PTB, PSC, PSP, PRP, PMN, PTdoB, PSD, PPR, PTR. 
No conjunto, a maior predominância partidária é do PMDB, com 20,6\% dos membros, e do PT (20,3\%), seguido, mas de longe, pelo PSDB (11,3\%). A participação de políticos eleitos pelo Partido dos Trabalhadores cresce gradualmente: em 1982 os deputados federais petistas representavam 3\% dos ex-funcionários públicos eleitos; em 2002, mesmo ano em que o partido elegeu o Presidente da República, essa participação chegou a 29,6\%; em 2010, contudo, ela diminuiu para $21,8 \%{ }^{8}$.

Essa distribuição entre os partidos, nesse contingente específico de deputados, está possivelmente relacionada à preferência do eleitorado. Samuels (2008, p. 305) aponta mudanças no apoio de PMDB, PSDB (centro) e PT (esquerda) no intervalo 1989-2008. A inclinação dos eleitores pelo PMDB caiu de $15 \%$ para $7 \%$, enquanto o PSDB no mesmo período conseguiu atrair somente uma média de 6\% e 7\% dos cidadãos brasileiros como apoiadores. E o PT fez o caminho inverso, foi de $5 \%$ em 1989 para $20 \%$ em 2004.

Assim, ao longo das oito legislaturas estudadas, houve uma mudança na hierarquia da participação de deputados eleitos por partidos de direita e esquerda. Esse fato pode ser explicado pelo crescimento do PT no parlamento nacional, mas também pela conquista do Governo Federal em 2002. No início da nossa série (1982), o PT possuía 1,7\% das cadeiras na Câmara dos Deputados; em 2002, 17,7\%; e em 2010, 17,1\%. O Gráfico 4 mostra a distribuição da presença de deputados da direita/centro/esquerda antes e depois de 2002 por resíduos padronizados.

No período compreendido entre a fase de transição da Ditadura Militar para a democracia até o Governo Cardoso, deputados eleitos com origem no funcionalismo público concentram-se nos partidos de direita $(2,1)$; após a eleição de Lula, nos partidos de esquerda $(3,3)$. Uma interpretação dessa evidência será feita a seguir.

\footnotetext{
${ }^{8}$ Esses dados diferem dos do estudo realizado por Rodrigues (2002), no qual o autor analisa a 51a legislatura (1998) da Câmara dos Deputados, em que PFL, o PMDB e o PSDB são os partidos que mais possuem ex-funcionários públicos. No entanto, é necessário ressaltar que, no estudo de Rodrigues (2002), foram excluídos da categoria de funcionários públicos os professores. Desse modo, em sua pesquisa, o PT contaria somente com $3 \%$ dos parlamentares oriundos do serviço público, enquanto que no nosso estudo, incluindo professores nesse grupo profissional, os deputados federais com origem no funcionalismo público filiados ao PT passam dos $20 \%$.
} 
Gráfico 4: Deputados com origem no funcionalismo público eleitos por bloco ideológico para a Câmara dos Deputados antes e depois de 2002 (resíduos padronizados)

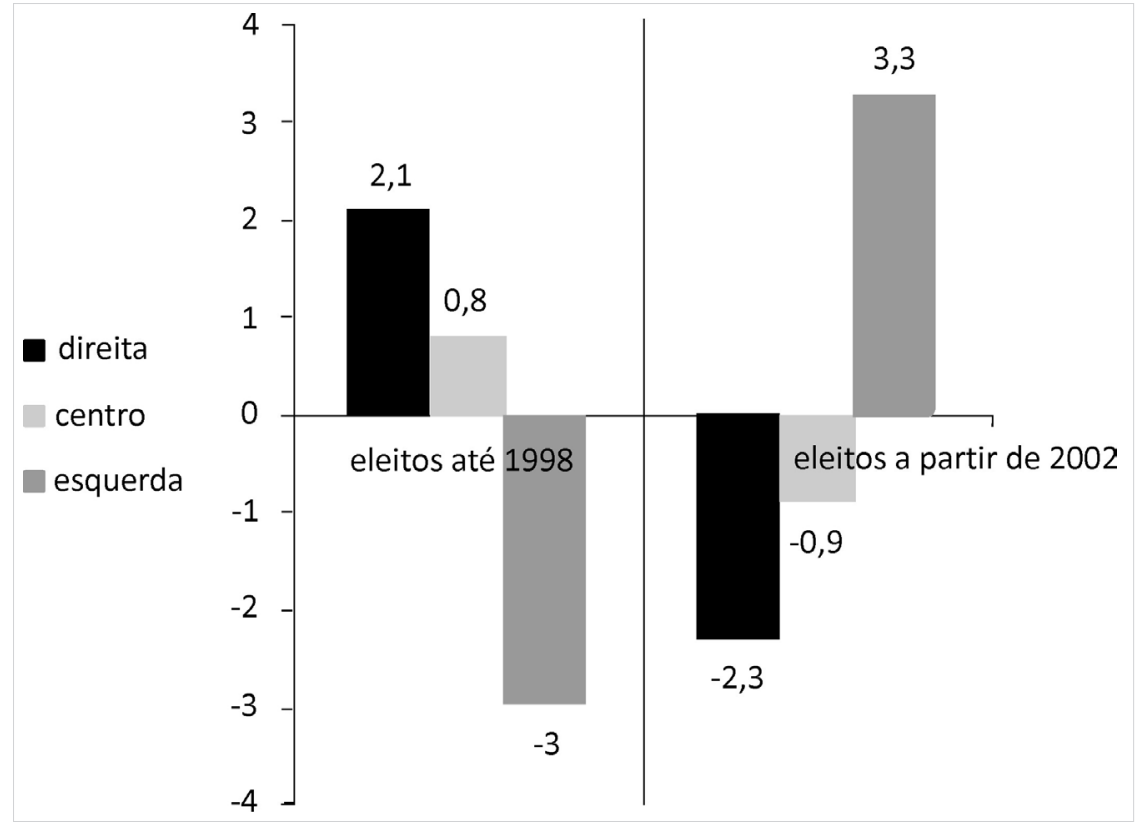

Fonte: Observatório de elites políticas e sociais do Brasil (NUSP/UFPR).

$\mathrm{N}=211 ;$ Mandatos $=462$

Esquerda: PDT, PT, PSB, PSOL, PPS, PC do B; Centro: PMDB, PSDB, PV; Direita: DEM/PFL, PPB, PP, PRB, PDS, PRN, PDC. PL/PR, PTB, PSC, PSP, PRP, PMN, PT do B, PSD, PPR, PTR.

\section{Considerações finais}

O objetivo deste trabalho foi explorar os dados sobre o perfil sociopolítico dos deputados com origem na burocracia pública eleitos no Brasil no ciclo político pós-ditatorial. Buscou-se fazer uma sociografia desse grupo para, posteriormente, propormos algumas explicações sobre a notável mudança de perfil dos eleitos entre 1982 e 2010.

Em geral, políticos que vêm do funcionalismo público são políticos inexperientes: quase $40 \%$ do universo estudado entrou na carreira política diretamente via Câmara dos Deputados. Todavia, esses perfis estão concentrados principalmente nas legislaturas iniciais do nosso ciclo (1982, 1986, 1990 e 1994). Após quatro legislaturas, o perfil do grupo muda. Apesar de uma parcela considerável ainda ingressar diretamente na política pelo Legislativo federal (cerca de 30\%), é o cargo de vereador que predominará como a porta de entrada de 1998 em diante. Em 2010, temos um fenômeno novo: a entrada na Câmara se distribui igualmente 
entre os cargos de vereador, deputado estadual e aqueles que já estreiam como deputados federais. Com isso, o cursus honorum desses parlamentares passa a ser mais linear, gradual e previsível. Um dado que ilustra também a transformação do perfil de carreira é a média de anos cumprida entre a entrada no serviço público e a entrada na Câmara dos Deputados: de 9 anos em 1982 para 18 anos em 2010.

Supôs-se que cargos públicos de alto escalão seriam uma porta de acesso mais rápida e/ou mais direta para as posições mais altas da carreira política, como é o caso do cargo de deputado no Legislativo federal. Os dados encontrados contrariam essa afirmação. A maioria desses parlamentares (40\%), considerando aqui todo o período, veio do médio funcionalismo. São principalmente professores universitários. Essa característica se intensifica de 1990 por diante e, em 2010, 40\% desses parlamentares vêm de postos de médio escalão, enquanto o alto escalão cai de $43 \%$ em 1990 para 22\% em 2010.

Por fim, entre os achados da pesquisa, a constatação mais notável é a inversão do volume de participação de deputados de esquerda e direita nesse contingente. Enquanto em 1982 os que estavam inscritos em partidos de direita representavam quase $60 \%$ do universo de funcionários eleitos, em 2010 esse percentual caiu para menos da metade, atingindo somente $25,5 \%$ do total. Em contrapartida, a presença de parlamentares de partidos de esquerda aumentou espetacularmente, passando de 2\%, em 1982, a 42\% do total dessa categoria na Câmara dos Deputados em 2010.

A hipótese sugerida no início deste artigo foi, portanto, parcialmente confirmada: há diferenças de perfil de carreira política entre indivíduos de diferentes escalões funcionais de origem. Mas são diferenças moderadas. Essa causa endógena à burocracia - o nível hierárquico de pertencimento no serviço público e todas as vantagens políticas que podem ser extraídas daí - parece ser menos importante do que uma causa exógena na definição das chances políticas de ser eleito: o pertencimento a determinado partido político e o lugar desse partido no espectro ideológico.

Assim, o achado mais revelador do artigo é a diferença do perfil desse grupo de parlamentares quando divididos por blocos ideológicos. Ao que parece, a filiação político-partidária (uma razão exógena à burocracia) interfere nos ativos políticos que os funcionários podem vir a mobilizar e condiciona seu acesso aos cargos eletivos, ou, ao menos, a esse cargo eletivo aqui estudado: deputado federal. O sucesso eleitoral dos servidores do Estado brasileiro depende menos de seus atributos, ou dos atributos ligados à sua função burocrática, e mais da força que o partido no governo pode exercer para a atração desses indivíduos ao mercado eleitoral e o impulso que pode, consequentemente, dar às suas respectivas carreiras políticas. 


\section{Referências bibliográficas}

Abreu, A. A. de et al. (EDS.). Dicionário histórico-biográfico brasileiro. Rio de Janeiro: Centro de Pesquisa e Documentação de História Contemporânea do Brasil/ Fundação Getúlio Vargas, 2001.

Braendle, T.; Stutzer, A. Public servants in Parliament: theory and evidence on its determinants in Germany. Public Choice, v. 145, n. 1-2, p. 223-252, 2010.

BRAendle, T.; Stutzer, A. Selection of public servants into politics. Working papers, p. 41, 2011.

CARVALHO, J. M. DE. A construção da ordem: a elite política imperial; Teatro de sombras: a política imperial. 2a. ed. Rio de Janeiro: Editora UFRJ; Relume-Dumará, 1996.

Codato, A.; COSTA, L. D.; CERVI, E. U. A direita brasileira em perspectiva histórica: uma socioanálise dos partidos de direita e dos seus políticos da democracia populista à democracia liberal (1945-2010)37 Encontro Anual da Anpocs. Anais...Águas de Lindoia - SP, Brasil: set. 2013

Codato, A.; COSTA, L. D.; MASsIMO, L. Coding Professions in Research with Political Elites: a Methodological and a Typological Discussion. 23rd IPSA World Congress of Political Science. Anais...Montréal, Canada: International Political Science Association - IPSA, jul. 2014

Codato, A. N. Uma história política da transição brasileira: da ditadura militar à democracia. Revista de Sociologia e Política, n. 25, p. 83-106, nov. 2005.

CoRAdINI, O. L. Cargos e funções públicas e candidaturas eleitorais. Sociedade e Estado, v. 27, n. 3, p. 689-708, 2012.

CottA, M.; TAvares de AlmeidA, P. From servants of the State to elected representatives: public sector background among members of Parliament. In: COTTA, M.; BEST, H. (Eds.). Democratic representation in Europe: change, diversity and convergence. Oxford: Oxford University Press, 2007. p. 51-76.

COTTA, M.; TAVARES DE ALMEIDA, P.; Roux, C. De serviteurs de l'État à représentants élus: les parlementaires originaires du secteur public en Europe. Pôle Sud, v. 21, n. 1, p. 101-122, 2004.

DoGAN, M. Les professions propices à la carrière politique. Osmoses, filières et viviers. In: OffERLÉ, M. (Ed.). La profession politique: XIXe-XXe siècles. Paris: Belin, 1999. p. 171-199.

EDINGER, L. J.; SEARING, D. D. Social background in elite analysis: a methodological inquiry. The American Political Science Review, v. 61, n. 2, p. 428-445, 1967.

FerreirA, A. P. L.; Lemos, M. W. DE; SiRINO, N. P. O perfil das deputadas federais com origem profissional no funcionalismo público eleitas entre 1982 e 2010 . Newsletter. Observatório de elites políticas e sociais do Brasil, NUSP/UFPR, v. 2, n. 8, p. 1-16, jun. 2015.

GAXIE, D. Les logiques du recrutement politique. Revue française de science politique, v. 30, n. 1, p. 5-45, 1980.

INTER-PARLIAMENTARY UNION. Women in national parliaments. World Classification. Situation as of 1st Januray 2014. Disponível em: <http://www.ipu.org/wmn-e/ classif.htm>. 
KUKLYS, M. Transformation of parliamentary elites: recruitment and careers of legislators in Estonia, Latvia and Lithuania, 1990-2012. [s.I.] Friedrich-SchillerUniversität Jena, 2013.

MAREnco dos SAntos, A. Nas fronteiras do campo político. Raposas e outsiders no Congresso Nacional. Revista Brasileira de Ciências Sociais, v. 12, n. 33, p. 87-101, fev. 1997.

MILLER, M. C. The high priests of American politics: the role of lawyers in American political institutions. Knoxville: University of Tennessee Press, 1995.

NEIVA, P.; IZUMI, M. Os "doutores" da federação: formação acadêmica dos senadores brasileiros e variáveis associadas. Revista de Sociologia e Política, v. 20, n. 41, p. 171-192, 2012.

NorRIS, P. Recrutamento político. Revista de Sociologia e Política, v. 21, n. 46, p. 11-32, jun. 2013.

NORRIS, P.; LOVENDUSKI, J. United Kingdom. In: NORRIS, P. (Ed.). Passages to power: legislative recruitment in advanced democracies. Cambridge: Cambridge University Press, 1997, p. 158-186.

Rodrigues, L. M. Partidos, ideologia e composição social: um estudo das bancadas partidárias na Câmara dos Deputados. São Paulo: Edusp, 2002.

Rodrigues, L. M. Mudanças na classe política brasileira. São Paulo: PubliFolha, 2006.

SAMUels, D. A evolução do petismo (2002-2008). Opinião Pública, v. 14, n. 2, p. 302-318, nov. 2008.

SOARES, N. C. R. A presença e o comportamento de políticos oriundos da burocracia do setor público na Câmara dos Deputados nas $51^{a}$ e $52^{a}$ legislaturas. Brasília - DF: Universidade do Legislativo Brasileiro; Universidade Federal de Mato Grosso do Sul, 2008.

TARouco, G. da S.; MADEIRA, R. M. Partidos, programas e o debate sobre esquerda e direita no Brasil. Revista de Sociologia e Política, v. 21, n. 45, p. 149-165, mar. 2013.

WEBER, M. The profession and vocation of politics. In: LASSMAN, P.; SPEIRS, R. (Eds.). Weber: political writings. Cambridge: Cambridge University Press, 1994. p. 309-369.

Adriano Codato

Doutor em Ciência Política (Unicamp). Professor Adjunto do Departamento de Ciência Política e Sociologia da Universidade Federal do Paraná (UFPR). Contato: adriano@ufpr.br

Ana Paula Lopes Ferreira

Mestranda em Ciência Política (UFPR) e pesquisadora do Núcleo de Pesquisa em Sociologia Política Brasileira do Departamento de Ciência Política e Sociologia da Universidade Federal do Paraná (UFPR). Contato: ana.lopes089@gmail.com

Luiz Domingos Costa

Doutorando em Ciência Política (UFPR) e pesquisador do Núcleo de Pesquisa em Sociologia Política Brasileira do Departamento de Ciência Política e Sociologia da Universidade Federal do Paraná (UFPR). Contato: luizdomingos@gmail.com 